\title{
Telepharmacy Knowledge, Perceptions, and Readiness among Future Malaysian Pharmacists Amid the COVID-19 Pandemic
}

\author{
Mohamed Hassan Elnaem ${ }^{1,2, *}$ Muhammad Eid Akkawi ${ }^{1,2}$, Abdul Kareem Al-Shami ${ }^{1,2}$, \\ Ramadan Elkalmi ${ }^{3,4}$ \\ ${ }^{1}$ Department of Pharmacy Practice, Faculty of Pharmacy, International Islamic University-Malaysia, Kuantan, Pahang, MALAYSIA. \\ ${ }^{2}$ Faculty of Pharmacy, Quality Use of Medicines Research Group, International Islamic University-Malaysia, Kuantan, \\ Pahang, MALAYSIA. \\ ${ }^{3}$ Department of Clinical Pharmacy and Therapeutics, Dubai College of Pharmacy, Dubai, UAE. \\ ${ }^{4}$ Faculty of Medicine, University of Sebha, Sabha, LIBYA.
}

\begin{abstract}
Background: Telepharmacy is a relatively recent advancement in healthcare services that enables providing high-quality pharmacy services to rural and remote areas. It gained increased attention during the COVID19 pandemic. Objectives: To assess the knowledge, perceptions, and readiness towards telepharmacy services among senior pharmacy students in a Malaysian public pharmacy school. Materials and Methods: A cross-sectional study was conducted using a self-developed, pre-tested, and validated 35-item questionnaire among penultimate and final year students in a Malaysian public pharmacy school. Ethical approval was obtained before beginning the online data collection between September and December 2020. Descriptive and inferential data analyses were performed using SPSS version 22. A p-value $\leq$ of 0.05 was considered statistically significant. Results: The study received a total of 178 responses to the questionnaire. The response rates of the third and fourth years were $50.6 \%$ and $49.4 \%$, respectively. Overall, $67 \%$ had high knowledge, and $68 \%$ showed high readiness level. Meanwhile, $61 \%$ of the responses had positive perceptions of telepharmacy services. A notably excellent knowledge was demonstrated in items related to the telepharmacy role during the pandemic $(93.8 \%)$ and the technical competencies required for the service provider $(96.1 \%)$. The beneficial role of telepharmacy to save patients' resources was perceived positively with a $91 \%$ agreement level among study participants. The readiness items related to the lack of incentive and the excessive workload were associated with less agreement levels of $33.7 \%$ and $45.5 \%$, respectively. Overall, participants' knowledge of telepharmacy significantly impacted their expressed readiness to implement telepharmacy services in their future practice. Conclusion: Most study participants had adequate knowledge, positive perceptions and demonstrated readiness to implement telepharmacy services in their future pharmacy practice. The potential increase in workload and lack of incentive were the main concerns associated with the widespread adoption of telepharmacy practice models.
\end{abstract}

Key words: Malaysia, Pharmacists, Readiness, Students, Telepharmacy.

\section{INTRODUCTION}

The term "Telemedicine" was introduced in the 1960s and has expanded to include all communication technology forms to ensure that health care and public education are provided in the countryside and remote areas. ${ }^{1}$ The Institute of Medicine defines telemedicine as "the use of information and communication technology (ICT) to deliver and support healthcare systems when patients are disconnected due to distance. ${ }^{2}$ According to the American Society of Health-System Pharmacists (ASHP), telepharmacy refers to pharmacists' use of telecommunications technology to monitor pharmacy operations and deliver patient care services. ${ }^{3}$ It appears to be a new
Submission Date: 07-06-2021; Revision Date: 07-09-2021; Accepted Date: 09-11-2021

DOI: 10.5530/ijper.56.1.2 Correspondence: Dr. Mohamed Hassan Elnaem, Pharm.D, PhD. Assistant Professor, Pharmacy Practice Department, Faculty of Pharmacy, International Islamic University-Malaysia, Jalan Sultan Ahmad Shah-25200 Kuantan, Pahang, MALAYSIA. E-mail: drmelnaem@iium. edu.my

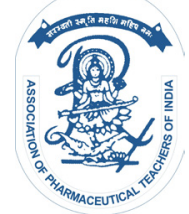

www.ijper.org 
platform that provides a unique and advanced method of providing quality pharmacy services to rural and remote areas. ${ }^{4}$ Common telepharmacy services include medication order review, dispensing medications, patient consultation and evaluation, therapeutic drug monitoring, and medication therapy management. ${ }^{5}$ These services can be conducted using electronic technology tools such as video conferencing, new systemic software applications, and automatic dispensing machines. ${ }^{6}$ Telepharmacy addresses access to healthcare services while also increasing the effectiveness of patient counseling provided by pharmacists through remote area networks. ${ }^{7}$ Also, it was found that telepharmacy offers better counseling in terms of privacy and session length and provides cost-effective health care services. ${ }^{8}$ Telepharmacy services gained more attention to allow remote pharmaceutical care services during the COVID19 pandemic, where several movement restrictions have been implemented globally. Therefore, the issue of the readiness of future health care providers to adopt the telepharmacy practice model needs to be further investigated. Several initiatives in pharmacy programs have focused on improving learners' communication skills. ${ }^{10}$ Previous reports showed that incorporating telepharmacy services into training programs for pharmacy students and integrating technology into pharmacy has expanded the understanding of drug therapy problems and their ability to communicate patient care plans. ${ }^{11,12}$ Moreover, strategies for appropriate technology-based education and training are still needed among students and practitioners. ${ }^{13}$ In Malaysia, the Ministry of Health initiated services such as teleconsulting and personalized health information in a plan towards implementing telemedicine. ${ }^{14}$ Therefore, future health care providers should be equipped with essential knowledge and skills for successful telepharmacy implementation. ${ }^{15}$ There is a scarcity of information on the level of knowledge, beliefs, and preparedness for telepharmacy among pharmacy students nearing graduation. Therefore, the purpose of this study was to assess the knowledge, perception, and readiness towards telepharmacy services among senior pharmacy students at a Malaysian public pharmacy school.

\section{MATERIALS AND METHODS}

\section{Study Design}

A cross-sectional study was conducted from September to December 2020 among senior pharmacy students in a Malaysian public pharmacy school to assess their knowledge, perceptions, and readiness towards telepharmacy.

\section{Study Subjects and Settings}

The study was conducted through an online survey using Google Forms among pre-final and final year pharmacy students in one of the main Malaysian public universities. We focused on senior undergraduate pharmacy students because they were exposed adequately to the core pharmacy practice courses. Additionally, participants must understand English, as the online survey was conducted in the English language. The subject's participation was voluntary, and no compensation was provided.

\section{Sample Size}

The sample size was calculated using the Raosoft calculator. The confidence level, the margin of error, and the response distribution were set at $95 \%, 5 \%$, and $50 \%$, respectively. Following the final calculation, the minimum recommended sample size for our study is 151 respondents.

\section{Study Procedure}

Formal ethical permission was obtained from the IIUM Research Ethics Committee (IREC) before the collection of data. Due to the COVID-19 pandemic, online questionnaires have been chosen as the platform to communicate with the study participants. Therefore, Google Form, an online survey platform, was used to distribute the questionnaires.

\section{Study Instrument}

A self-designed 35-item structured questionnaire was developed as no valid instrument was found in the literature. Three pharmacy academicians reviewed the content validity of the questionnaire after considering their experience and knowledge of the research topic. Since the validation process involved three pharmacy academicians, the acceptable item-level content validity index was 1. After considering all the experts' inputs, the final survey was reduced from 54 to 35 items. The survey was composed of four sections; section A for demographic information; section $\mathrm{B}$, which consisted of 10 items for knowledge measured on a true, false, and not sure scale; section C, which contained 13 items for perceptions; and section D, which included 12 items for readiness. Responses for both perceptions and readiness were collected on a 5 -item Likert scale. At the researchers' discretion, the total score of each section was used to categorize responses into low $\leq 40 \%$, medium $41 \%-74 \%$, and high $\geq 75 \%$. 


\section{Statistical Analysis}

The data were analyzed using SPSS software, version 22. The descriptive data were analyzed using percentages and frequencies. The Chi-square test was used to see whether third-year and fourth-year students' questionnaire responses differed significantly. In addition, the Mann-Whitney $U$ test was used to investigate potential associations between knowledge and readiness items. The level of significance was set at $p<0.05$.

\section{RESULTS}

\section{Demographic information}

The study received 178 responses to the questionnaire, exceeding the minimum required sample with 27 responses. The response rates for the third and fourth years were $50.6 \%$ and $49.4 \%$, respectively. Overall, $67 \%$ had high knowledge, and $68 \%$ showed a high readiness level. Meanwhile, $61 \%$ of the responses had positive perceptions of telepharmacy services.

\section{Students' knowledge on telepharmacy}

For this section, the overall average level of knowledge among study participants was $67 \%$. Overall, there were no significant differences based on years of study, except for the first item related to the status of telepharmacy practice in Malaysia $(p=0.001)$. In addition, notably excellent knowledge was demonstrated in items related to the telepharmacy role during the pandemic (93.8\%) and the technical competencies required for the service provider $(96.1 \%)$. The responses of students regarding their knowledge of telepharmacy are presented in Table 1.

\section{Students' perceptions of telepharmacy}

On average, $61 \%$ of the responses showed positive perceptions towards telepharmacy. Three items showed less than $50 \%$ agreement level on the measurement scale, such as the effectiveness of patient consultation via telepharmacy $(40.4 \%)$. Meanwhile, the highest agreement level $(91 \%)$ was related to the item focusing on the beneficial role of telepharmacy in saving patients' resources. Most items revealed no significant difference in favorable telepharmacy implementation in Malaysia between the third and fourth-year students. Table 2 displays the responses related to the perceptions of students regarding telepharmacy.

\section{Students' readiness toward telepharmacy and its associations with knowledge level}

Table 3 shows the overall responses to the 12 items in Section D of the readiness assessment. The participants reported, on average, 68\% readiness towards telepharmacy implementation and its associated requirements. The items related to the lack of incentive and the excessive workload were associated with less readiness among participants, with agreement levels of $33.7 \%$ and $45.5 \%$, respectively. The highest expressed readiness levels were linked to participants' willingness to undertake required training and use of mobile technology in their future telepharmacy practice. Furthermore, the findings showed significant associations between knowledge and readiness items. Overall, participants' knowledge of telepharmacy significantly impacted their expressed readiness to

\begin{tabular}{|c|c|c|}
\hline & $\begin{array}{c}\text { Not sure, } \\
\text { No } \\
\text { N (\%) }\end{array}$ & $\begin{array}{l}\text { Yes } \\
\mathrm{N}(\%)\end{array}$ \\
\hline $\mathrm{K} 1$. Telepharmacy is available in Malaysia & $81(45.5)$ & $97(54.5)$ \\
\hline $\begin{array}{l}\text { K2. Information Communication Technology (ICT) knowledge is important for pharmacists on how to } \\
\text { conduct telepharmacy. }\end{array}$ & $7(3.9)$ & 171(96.1) \\
\hline K3. Telepharmacy played a big role during COVID-19 outbreak around the world. & $11(6.2)$ & 167(93.8) \\
\hline K4. Telepharmacy does require strong internet connection or high-performance technology. & $54(30.3)$ & 124(69.7) \\
\hline K5. Telepharmacy provides better counseling in terms of privacy and length of the session. & $76(42.7)$ & 102(57.3) \\
\hline K6. Telepharmacy solves the waiting time problem in most general hospitals. & $17(9.6)$ & $161(90.4)$ \\
\hline K7. Telepharmacy is also involved in ADR monitoring and reporting. & $60(33.7)$ & 118(66.3) \\
\hline $\begin{array}{l}\text { K8. In general hospitals, telepharmacy is conducted by drug information service during office hours and by } \\
\text { emergency departments after office hours. }\end{array}$ & $56(31.5)$ & 122(68.5) \\
\hline K9. Patients from rural areas can have more medication access and information via telepharmacy. & $60(33.7)$ & 118(66.3) \\
\hline $\begin{array}{l}\text { K10. Telepharmacy services can extend hospital pharmacy services outside office hours that do not offer } \\
\text { round-the-clock pharmacy services. }\end{array}$ & $46(25.8)$ & 132(74.2) \\
\hline
\end{tabular}


Table 2: Responses to telepharmacy perceptions items ( $n=178)$.

\begin{tabular}{|l|c|c|c|} 
& $\begin{array}{c}\text { Strongly } \\
\text { disagree, } \\
\text { Disagree } \\
\text { N (\%) }\end{array}$ & $\begin{array}{c}\text { Neutral } \\
\text { N (\%) }\end{array}$ & $\begin{array}{c}\text { Strongly } \\
\text { agree, Agree } \\
\text { N (\%) }\end{array}$ \\
\hline P1. Do you think telepharmacy will improve the patient's adherence to the medication? & $6(3.4)$ & $33(18.5)$ & $139(78.1)$ \\
\hline $\begin{array}{l}\text { P2. Do you agree telepharmacy will have a higher error rate for medication dispensing } \\
\text { and filling, as compared to traditional pharmacy? }\end{array}$ & $31(17.4)$ & $88(49.4)$ & $59(33.1)$ \\
\hline $\begin{array}{l}\text { P3. Do you feel telepharmacy will enhance the patient's access to the medication, } \\
\text { especially those who are in rural areas? }\end{array}$ & $13(7.3)$ & $29(16.3)$ & $136(76.4)$ \\
\hline $\begin{array}{l}\text { P4. Do you think telepharmacy will provide the complete privacy setting during the } \\
\text { consultation period? }\end{array}$ & $11(6.2)$ & $39(21.9)$ & $128(71.9)$ \\
\hline $\begin{array}{l}\text { P5. Based on your opinion, do you agree telepharmacy will increase the pharmacist's } \\
\text { workload and commitment? }\end{array}$ & $19(10.7)$ & $64(36.0)$ & $95(53.4)$ \\
\hline $\begin{array}{l}\text { P6. Do you think telepharmacy is able to help patients save their money and travel } \\
\text { time to reach the healthcare facilities? }\end{array}$ & $0(0)$ & $16(9.0)$ & $162(91.0)$ \\
\hline $\begin{array}{l}\text { P7. Are you willing to share your personal information on the online database when } \\
\text { using telepharmacy services? }\end{array}$ & $22(12.4)$ & $58(32.6)$ & $98(55.1)$ \\
\hline $\begin{array}{l}\text { P8. Do you think telepharmacy can minimize the cost to establish pharmaceutical } \\
\text { business in comparison to regular pharmacy? }\end{array}$ & $12(6.7)$ & $59(33.1)$ & $107(60.1)$ \\
\hline P9. Do you think patient consultation via telepharmacy will be effective? & $36(20.2)$ & $70(39.3)$ & $72(40.4)$ \\
\hline $\begin{array}{l}\text { P10. Do you think pharmacy schools should provide education programs on } \\
\text { computers, IT, and telepharmacy to assist in future utilization of telepharmacy? }\end{array}$ & $4(2.2)$ & $26(14.6)$ & $148(83.1)$ \\
\hline $\begin{array}{l}\text { P11. Do you think therapeutic drug monitoring via telepharmacy in rural areas will be } \\
\text { easily monitored? }\end{array}$ & $71(39.9)$ & $54(30.3)$ & $53(29.8)$ \\
\hline $\begin{array}{l}\text { P12. Do you agree that security is a greater concern in a remote site telepharmacy } \\
\text { than in a traditional community pharmacy? }\end{array}$ & $9(5.1)$ & $48(27.0)$ & $121(68.0)$ \\
\hline $\begin{array}{l}\text { P13. Scarcity of pharmacists has caused a situation where medications are supplied } \\
\text { without the involvement of pharmacists. Do you agree that telepharmacy is able to } \\
\text { help to minimize this scarcity? }\end{array}$ & $22(12.4)$ & $64(36.0)$ & $92(51.7)$ \\
\hline
\end{tabular}

Table 3: Responses to telepharmacy readiness items ( $n=178)$.

\begin{tabular}{|c|c|c|c|}
\hline & $\begin{array}{c}\text { Strongly } \\
\text { disagree, } \\
\text { Disagree } \\
\mathbf{N}(\%)\end{array}$ & $\begin{array}{c}\text { Neutral } \\
\mathbf{N}(\%)\end{array}$ & $\begin{array}{c}\text { Strongly } \\
\text { agree, } \\
\text { Agree } \\
\text { N (\%) } \\
\end{array}$ \\
\hline R1. I am ready to work on telepharmacy projects in rural areas, even without an incentive. & $55(30.9)$ & $63(35.4)$ & $60(33.7)$ \\
\hline R2. I am ready to work after office hours if needed. & $33(18.5)$ & $64(36.0)$ & $81(45.5)$ \\
\hline $\begin{array}{l}\text { R3. I am ready to conduct drug counseling via two-way video consultation such as } \\
\text { telephone call, text message, or voice call through mobile applications. }\end{array}$ & $6(3.4)$ & $26(14.6)$ & $146(82.0)$ \\
\hline $\begin{array}{l}\text { R4. I am ready to teach the patients how to use their drug delivery device (e.g., inhaler, } \\
\text { insulin pen) properly through video consultation. }\end{array}$ & 10(5.6) & $35(19.7)$ & $133(74.7)$ \\
\hline R5. I am ready to undergo training in ethics and legal issues related to telepharmacy. & $4(2.2)$ & $24(13.5)$ & $150(84.3)$ \\
\hline R6. I am ready to face the implementation of telepharmacy in all healthcare settings. & $1(0.6)$ & $39(21.9)$ & $138(77.5)$ \\
\hline $\begin{array}{l}\text { R7. I am ready to conduct Home Medication Review (HMR) through telepharmacy, } \\
\text { especially in rural and remote communities. }\end{array}$ & $15(8.4)$ & $38(21.3)$ & $125(70.2)$ \\
\hline $\begin{array}{l}\text { R8. I am ready to improve and reduce the risk of medication errors among patients through } \\
\text { telepharmacy. }\end{array}$ & $5(2.8)$ & $34(19.1)$ & $139(78.1)$ \\
\hline R9. I am ready to carry the increment of workload when conducting telepharmacy. & $24(13.5)$ & $74(41.6)$ & $80(44.9)$ \\
\hline R10. I am ready to conduct medication reconciliation via telepharmacy services. & $8(4.5)$ & $50(28.1)$ & 120(67.4) \\
\hline $\begin{array}{l}\text { R11. I am ready to perform remote prescription checking before dispensing drugs from an } \\
\text { automated medication dispensing cabinet. }\end{array}$ & $9(5.1)$ & $41(23.0)$ & 128(71.9) \\
\hline $\begin{array}{l}\text { R12. I am ready to use mobile applications and the Internet to receive refill orders from } \\
\text { patients and transfer prescriptions. }\end{array}$ & $1(0.6)$ & $27(15.2)$ & 150(84.3) \\
\hline
\end{tabular}


Table 4: Associations between knowledge and readiness items.

\begin{tabular}{|c|c|c|}
\hline Independent knowledge items & Dependent readiness items & $P$-value* \\
\hline \multirow[t]{6}{*}{$\begin{array}{l}\text { K3. Telepharmacy played a big role during COVID-19 outbreak } \\
\text { around the world. }\end{array}$} & $\begin{array}{l}\text { R4. I am ready to teach the patients how to use } \\
\text { their drug delivery device (e.g., inhaler, insulin pen) } \\
\text { properly through video consultation. }\end{array}$ & 0.026 \\
\hline & $\begin{array}{l}\text { R6. I am ready to face the implementation of } \\
\text { telepharmacy in all healthcare settings. }\end{array}$ & 0.001 \\
\hline & $\begin{array}{l}\text { R7. I am ready to conduct Home Medication Review } \\
\text { (HMR) through telepharmacy, especially in rural and } \\
\text { remote communities. }\end{array}$ & 0.002 \\
\hline & $\begin{array}{l}\text { R8. I am ready to improve and reduce the risk } \\
\text { of medication errors among patients through } \\
\text { telepharmacy. }\end{array}$ & 0.031 \\
\hline & $\begin{array}{l}\text { R9. I am ready to carry the increment of workload } \\
\text { when conducting telepharmacy. }\end{array}$ & 0.005 \\
\hline & $\begin{array}{l}\text { R12. I am ready to use mobile applications and the } \\
\text { Internet to receive refill orders from patients and } \\
\text { transfer prescriptions. }\end{array}$ & 0.001 \\
\hline $\begin{array}{l}\text { K5. Telepharmacy provides better counseling in terms of privacy } \\
\text { and length of the session. }\end{array}$ & $\begin{array}{l}\text { R7. I am ready to conduct Home Medication Review } \\
\text { (HMR) through telepharmacy, especially in rural and } \\
\text { remote communities. }\end{array}$ & 0.031 \\
\hline \multirow[t]{2}{*}{$\begin{array}{l}\text { K6. Telepharmacy solves the waiting time problem in most } \\
\text { general hospitals. }\end{array}$} & $\begin{array}{l}\text { R6. I am ready to face the implementation of } \\
\text { telepharmacy in all healthcare settings. }\end{array}$ & 0.003 \\
\hline & $\begin{array}{l}\text { R12. I am ready to use mobile applications and the } \\
\text { Internet to receive refill orders from patients and } \\
\text { transfer prescriptions. }\end{array}$ & 0.006 \\
\hline $\begin{array}{l}\mathrm{K} 7 \text {. Telepharmacy is also involved in ADR monitoring and } \\
\text { reporting. }\end{array}$ & $\begin{array}{l}\text { R6. I am ready to face the implementation of } \\
\text { telepharmacy in all healthcare settings. }\end{array}$ & 0.015 \\
\hline \multirow{2}{*}{$\begin{array}{l}\text { K8. In general hospitals, Telepharmacy is conducted by drug } \\
\text { information service during office hours and by emergency } \\
\text { departments after office hours. }\end{array}$} & R2. I am ready to work after office hours if needed. & 0.009 \\
\hline & $\begin{array}{l}\text { R3. I am ready to conduct drug counseling via two- } \\
\text { way video consultation such as telephone call, text } \\
\text { message, or voice call through mobile applications. }\end{array}$ & 0.013 \\
\hline \multirow{2}{*}{$\begin{array}{l}\text { K9. Patients from rural areas can have more medication access } \\
\text { and information via Telepharmacy. }\end{array}$} & R2. I am ready to work after office hours if needed. & 0.038 \\
\hline & $\begin{array}{l}\text { R6. I am ready to face the implementation of } \\
\text { telepharmacy in all healthcare settings. }\end{array}$ & 0.041 \\
\hline
\end{tabular}

*Mann-Whitney U test

implement telepharmacy services in their future practice. For example, recognizing the potential role of telepharmacy in providing remote pharmaceutical care services during the pandemic (K3) was linked to an increase in six readiness domains to implement and undertake all the provider-related roles. Also, the knowledge of telepharmacy benefits (K6) was significantly associated with the readiness to implement telepharmacy considering all its technological requirements. A detailed explanation of the correlated items between the knowledge and readiness sections is presented in Table 4.

\section{DISCUSSION}

This study explored the senior pharmacy students' knowledge, perceptions, and readiness for telepharmacy services. It was found that students in their third and fourth years have roughly comparable levels of knowledge about telepharmacy, indicating the same level of exposure to academic subjects closely related to telepharmacy. There was some variation and uncertainty in responses to the first item regarding the availability of telepharmacy in Malaysia, which could be explained by the fact that it has not yet been fully developed and made widely available. The first attempt to involve pharmacists in virtual health care services was initiated in a collaborative program with the World Health Organization (WHO) to develop Drug Information Services (DIS) through a virtual network. ${ }^{16}$ Most participants emphasized the importance of Information Communication Technology (ICT) knowledge for pharmacists to conduct telepharmacy. It can be supported by previous research, which reported that more than $50 \%$ of healthcare providers agreed that ICT knowledge determined their attitudes towards telepharmacy. ${ }^{17}$ Hence, ICT knowledge is crucial for pharmacists to 
understand and implement better telepharmacy services to improve patients' outcomes when implementing such services. The findings also highlighted the significant role that telepharmacy played during the COVID-19 pandemic. Many healthcare providers use telepharmacy services to improve patient access to pharmaceutical care, allowing for more efficient delivery of care and reducing medication errors. ${ }^{18}$ Regarding the clinical benefits of telepharmacy, the findings revealed that most students agreed that telepharmacy could improve medication access for patients in rural areas. Similar data were provided in a cross-sectional study to assess pharmacists' perspectives in hospitals and community pharmacies on the clinical benefit and challenges of telepharmacy. ${ }^{19}$ Medication access and information in rural areas via telepharmacy would help eliminate prominent barriers such as travel time and expense and subsequently improve patient trust and satisfaction with telepharmacy service.

In general, study participants had positive perceptions of implementing telepharmacy in Malaysia since telepharmacy could enhance students' preparation to determine patient care interventions. The perceptions of the future pharmacists in our study contradicted what has been highlighted among healthcare providers in critical care who reported skepticism and uncertainty about the efficiency of telemedicine to deliver quality patient care. ${ }^{20}$ Affected by a lack of prior experience, some participants agreed with the statement that telepharmacy would possibly be associated with a higher medication error rate. Previous research highlighted that prior exposure was essential for pharmacy students to know whether telepharmacy would be related to a higher error rate or not. ${ }^{19}$ As highlighted earlier, telepharmacy could help decrease medication error rates, improve the quality of private counseling, and provide new channels for education programs. ${ }^{21}$ Participants' perceptions of the telepharmacy service appear favorable, but they remain uncertain about the scope of potential benefits and consequences. Most of the students believed that telepharmacy could minimize the current scarcity of pharmacists. This perception is supported by studies that discovered telepharmacy as a solution to the pharmacy workforce shortage, in which pharmaceutical services are provided remotely. ${ }^{21}$ Nonetheless, respondents were skeptical about the possibility of applying particular services such as therapeutic drug monitoring through telepharmacy. Also, participants appeared to be concerned about the potential increase in the usual workload imposed by telepharmacy service components, which they saw as barriers. However, other evidence highlights that telepharmacy practice barriers are more towards service payment and reimbursement issues. ${ }^{15}$ Security was considered by most students to be a greater concern in telepharmacy than in traditional community pharmacies. Again, this could be attributed to a lack of previous experience in telepharmacy services. Furthermore, the students agreed that pharmacy schools should offer education programs in computer science, information technology, and telepharmacy in preparation for future telepharmacy use, which corresponds to an Italian study that established the importance of IT knowledge for pharmacy students to equip them with essential skills for their future professional practice. ${ }^{22}$ The evidence is also supported by another study that mentioned that the quality of technology provided, reliable internet connections, and optimal utilization of the technology could influence telepharmacy services. ${ }^{19}$ Concerning their readiness to implement telepharmacy services in their future practice, there was a consistent agreement among study participants to undertake all activities and training relevant to telepharmacy practice. This could indicate the proper understanding of the potential role that telepharmacy could have in the future pharmacy practice models nationally, particularly amid the COVID-19 pandemic. ${ }^{23,24}$ Interestingly, most of the students were ready to carry the increment in workload when conducting telepharmacy. However, they expressed their concern about the lack of incentive for extended telepharmacy services, as most students would not agree to work on telepharmacy projects without incentive. In an Iranian study conducted to explore pharmacists' views on telepharmacy, the same issue of incentive and reimbursement has emerged as a significant barrier for the telepharmacy practice model. ${ }^{15}$ Consequently, a sustainable telepharmacy practice model should carefully consider essential training, balanced workload, and reimbursement for service providers.

This work is not without limitations. First, the survey was answered by participants who belonged to one university, so the generalizability of the findings is uncertain. Second, little work was conducted among senior pharmacy students that restricted us from properly comparing our findings to others.

\section{CONCLUSION}

Most study participants had adequate knowledge, positive perceptions and demonstrated readiness to implement telepharmacy services in their future pharmacy practice. However, they expressed concerns about the potential for an increased workload and a lack of incentive associated with the widespread adoption of telepharmacy practice models. It is suggested that the 
sustainable telepharmacy practice model should carefully consider the essential training, balanced workload, and reimbursement for service providers. This study may support the future implementation of telepharmacy pharmaceutical care services in full capacity in Malaysia. Also, it might aid academic initiatives in expanding the inclusion of telepharmacy practice models as a subject course in the curriculum, thereby better preparing future healthcare providers to perform their role effectively in delivering telepharmacy services.

\section{Funding}

This study was supported by grant no. RC-RIGS20-006-0006 from research management center, International Islamic University Malaysia.

\section{ACKNOWLEDGEMENT}

The authors acknowledge the contribution in the data collection phase made by Mr. Muhammad Adib Aqmal, Mr. Muhammad Hafiz Abd Rahim, Mr. Mohammad Adam Al-haqimy, Mr. Mohammad Aizat Hakim, Mr. Amri Nurhakim, Ms. Nadhrah Syamimi, Ms. Nur Shadia, and Ms. Nurul Hanis Mohd Sabari.

\section{CONFLICT OF INTEREST}

The authors declare no conflict of interest.

\section{ABBREVIATIONS}

WHO: World Health Organization; DIS: Drug Information Services; ICT: Information Communication Technology; ASHP: American Society of Health-System Pharmacists.

\section{REFERENCES}

1. Angaran DM. Telemedicine and telepharmacy: Current status and future implications. Vol. 56, American Journal of Health-System Pharmacy. American Society of Health-Systems Pharmacy; 1999. p. 1405-26.

2. Rawashdeh M, al Zamil MG, Hossain MS, Samarah S, Amin SU, Muhammad G. Reliable service delivery in Tele-health care systems. Journal of Network and Computer Applications. 2018 Aug 1;115:86-93.

3. Alexander E, Butler CD, Darr A, Jenkins MT, Long RD, Shipman CJ, et al. ASHP Statement on telepharmacy. American Journal of Health-System Pharmacy [Internet]. 2017 May 1 [cited 2020 May 21];74(9):e236-41. Available from: https://academic.oup.com/ajhp/article/74/9/e236/5102780

4. Kimber MB, Peterson GM. Telepharmacy-Enabling Technology to Provide Quality Pharmacy Services in Rural and Remote Communities. Journal of Pharmacy Practice and Research. 2006 Jun;36(2):128-33.

5. Margolis A, Young H, Lis J, Schuna A, Sorkness CA. A telepharmacy intervention to improve inhaler adherence in veterans with chronic obstructive pulmonary disease. Vol. 70, American Journal of Health-System Pharmacy. American Society of Health-Systems Pharmacy; 2013. p. 1875-6.
6. Keeys C, Kalejaiye B, Skinner M, Eimen M, Neufer JA, Sidbury G, et al. Pharmacist-managed inpatient discharge medication reconciliation: A combined onsite and telepharmacy model. American Journal of HealthSystem Pharmacy. 2014;71(24):2159-66.

7. Omran S, Elnaem MH, Ellabany N. Telepharmacy Knowledge, Attitude and Practice among Egyptian Pharmacists amid the COVID-19 Pandemic. In American College of Clinical Pharmacy; 2021 [cited 2021 Nov 3]. Available from: https://accp.confex.com/accp/2021am/meetingapp.cgi/Paper/57976

8. Garrelts JC, Gagnon M, Eisenberg C, Moerer J, Carrithers JOE. Impact of telepharmacy in a multihospital health system. American Journal of HealthSystem Pharmacy. 2010 Sep;67(17):1456-62.

9. Hedima EW, Okoro RN. Telepharmacy: An opportunity for community pharmacists during the COVID-19 pandemic in Sub Saharan Africa. Health Policy and Technology. 2020;

10. Elnaem $M H$, Jamshed $S Q$, Elkalmi RM. The future of pharmaceutical care in Malaysia: Pharmacy students 'perspectives. Pharmacy Education. 2017;17(1):215-22.

11. Smith MA, Benedict N. Effectiveness of educational technology to improve patient care in pharmacy curricula. Vol. 79, American Journal of Pharmaceutical Education. American Association of Colleges of Pharmacy; 2015. p. 1-10.

12. Alfaar AS, Kamal S, Abouelnaga S, Greene WL, Quintana Y, Ribeiro RC, et al. International telepharmacy education: Another venue to improve cancer care in the developing world. In: Telemedicine and e-Health. Mary Ann Liebert, Inc.; 2012. p. 470-4.

13. Elnaem $\mathrm{MH}$, Jamshed S. Mobile applications in clinical practice: What is needed in the pharmacy scenario? Archives of Pharmacy Practice [Internet]. 2017;8(1):3. Available from: http://www.archivepp.com/text. asp?2017/8/1/3/199619

14. Mat Som MH, Norali AN, Megat Ali MSA. Telehealth in Malaysia - An overview. ISIEA 2010 - 2010 IEEE Symposium on Industrial Electronics and Applications. 2010;660-4.

15. Ameri A, Salmanizadeh F, Keshvardoost S, Bahaadinbeigy K. Investigating Pharmacists' Views on Telepharmacy: Prioritizing Key Relationships, Barriers, and Benefits. Journal of Pharmacy Technology [Internet]. 2020 Oct 7 [cited 2021 Apr 28];36(5):171-8. Available from: http://journals.sagepub.com/ doi/10.1177/8755122520931442

16. Syed Azhar SS, Rahmat A, Jamal M. Malaysia Pharmaceutical Society Telepharmacy. 2002.

17. GSJ DE-, 2017 undefined. Knowledge and Attitude of The Physicians Toward Telemedicine. GlobalscientificjournalCom. 2017;5(June).

18. Ibrahim OM, Ibrahim RM, Z Al Meslamani A, Al Mazrouei N. Role of telepharmacy in pharmacist counselling to coronavirus disease 2019 patients and medication dispensing errors. Journal of Telemedicine and Telecare. 2020;

19. Poudel A, Nissen L. Telepharmacy: a pharmacist\&rsquo;s perspective on the clinical benefits and challenges. Integrated Pharmacy Research and Practice. 2016 Oct; Volume 5:75-82.

20. Shahpori R, Hebert M, Kushniruk A, Zuege D. Telemedicine in the intensive care unit environment-A survey of the attitudes and perspectives of critical care clinicians. Journal of Critical Care. 2011;26(3):328.e9-328.e15.

21. Baldoni S, Amenta F, Ricci G. Telepharmacy services: Present status and future perspectives: A review. Medicina (Lithuania). 2019;55(7).

22. Sankaranarayanan J, Murante LJ, Moffett LM. A Retrospective Evaluation of Remote Pharmacist Interventions in a Telepharmacy Service Model Using a Conceptual Framework. Telemedicine and e-Health. 2014 Oct;20(10):893901.

23. Le T, Toscani M, Colaizzi J. Telepharmacy: A New Paradigm for Our Profession. Journal of Pharmacy Practice. 2020;33(2):176-82.

24. Elnaem MH, Cheema E. Caring for patients with diabetes during COVID-19 pandemic: Important considerations for pharmacists. Research in social \& administrative pharmacy : RSAP [Internet]. 2020;(May):0-1. Available from: http://www.ncbi.nlm.nih.gov/pubmed/32507575. 


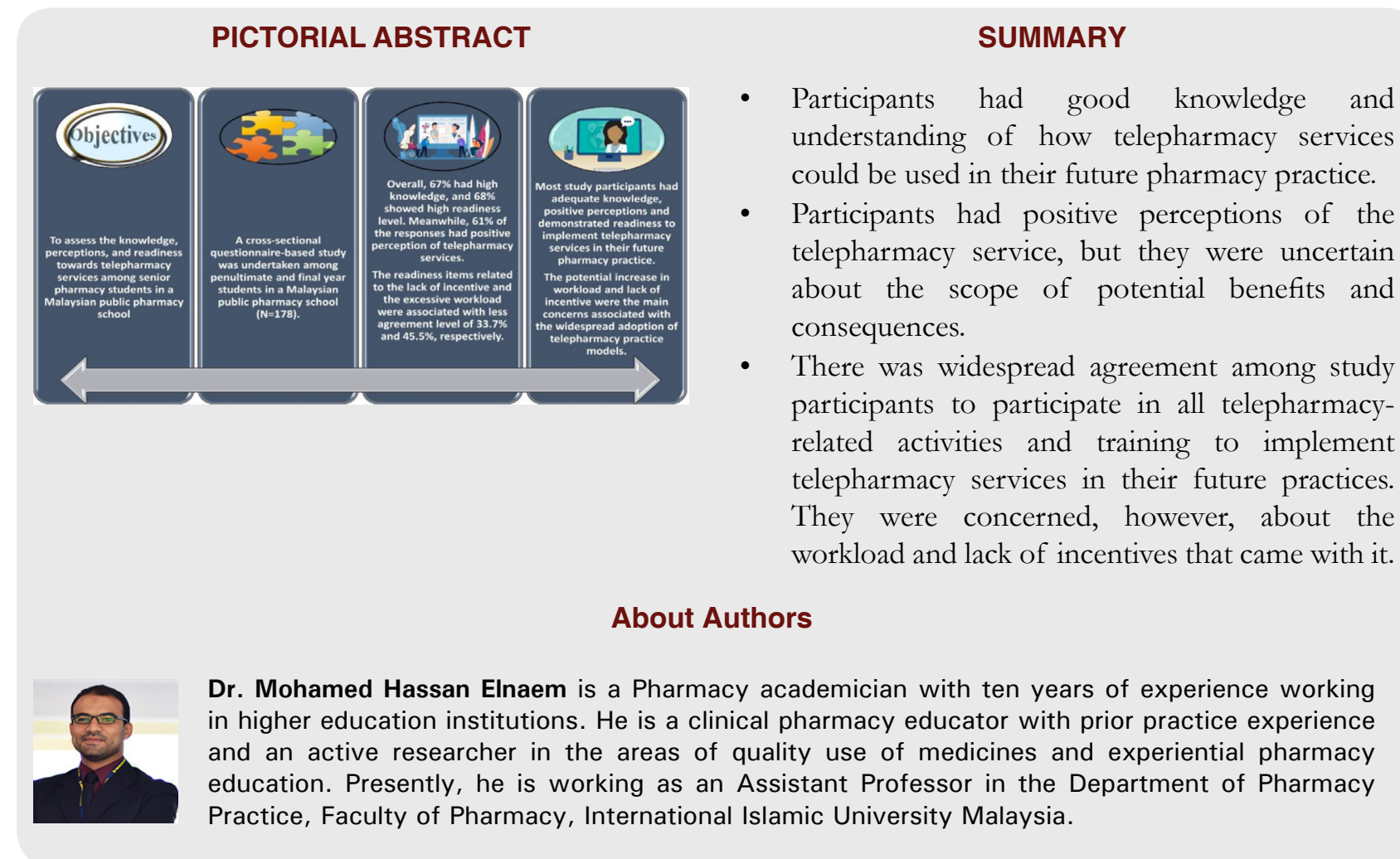

Cite this article: Elnaem MH, Akkawi ME, Al-shami AK, Elkalmi R. Telepharmacy Knowledge, Perceptions, and Readiness among Future Malaysian Pharmacists Amid the COVID-19 Pandemic. Indian J of Pharmaceutical Education and Research. 2022;56(1):9-16. 